\title{
Seismic Performance Assessment of RC Moment Frames Considering Stiffness Modification in Nonlinear Concentrated Plasticity Formulation for Modeling Damping
}

\author{
Negar Mohammadgholibeyki ${ }^{1}$
}

\begin{abstract}
In order to alleviate the problems regarding conventional damping modeling techniques in nonlinear structural simulations, using concentrated plasticity formulation including rotational end springs with no damping plus middle elastic parts with modified assigned damping has recently been proposed. However, a proper selection for springs' stiffness is a source of contention. In this paper, the effect of choosing different ratios for springs' rotational stiffness to the elastic part of the elements on the seismic performance of RC moment frames was investigated. Incremental Dynamic Analysis (IDA) was performed and the derived responses were used for seismic performance assessment methodology. The results demonstrate that using flexible springs may lead to a greatly conservative estimation of collapse capacity, annual losses, and repair costs compared to a rigid one. Due to lack of experimental data, it is not possible to certainly assert the most appropriate ratio. However, such variation in the seismic performance of a building model with different stiffness modification necessitates more investigation on this modeling strategy.
\end{abstract}

Keywords: Concentrated plasticity, damping, rotational stiffness, seismic performance, collapse capacity, loss estimation

${ }^{1}$ Corresponding Author. (negarmgbeyki@gmail.com)

M.Sc. Graduated, Department of Civil and Environmental Engineering, Amirkabir University of Technology, No.

350, Hafez Ave, Tehran, Iran 


\section{Introduction:}

Basically, there are two approaches for modeling nonlinear behavior in structures: 1) distributed plasticity, in which nonlinearity is probable to occur over the entire length of element [1] [2], 2) concentrated plasticity, in which the element is divided into an elastic part in the middle and two end rotational springs with a potential to simulate inelastic behavior [3]. Generally, as it is not simple to model deterioration caused by reinforcement local buckling and nonlinear interaction of shear and flexural in distributed plasticity models, using concentrated plasticity formulation for some cases is more rational [4].

Finding an appropriate and reliable damping modeling method to be implemented in inelastic models has been a challenge for researchers in the last decades, due to its unknown characteristic. Numerous studies have been conducted to assess different repercussions of using conventional damping modeling techniques, which are typically Rayleigh damping based on mass, initial, or tangent stiffness matrix, and also proposed novel methods for considering damping in structures. Rayleigh damping is represented by the following equation where damping matrix is defined by the linear combination of mass and stiffness matrices [5]:

$$
C=a_{0} M+a_{1} K
$$

$\mathrm{M}$ and $\mathrm{K}$ are mass and stiffness matrices; $\alpha$ and $\beta$ are proportionality terms respectively.

Studies done by Hall [6], Charney [7], Erduran, [8], Petrini et.al [9], Chopra and McKenna [10] , Hardyniec and Charney [11], Mohammadgholibeyki and Banazadeh [12], Anajafi et al. [13] (with the focus on based-isolated structures) show that using Rayleigh damping based on initial stiffness of the structure leads to the unrealistic estimation of demand and strength of the structure. Then, various strategies and remedies for considering damping in nonlinear structural models were introduced and investigated. Hall [6] suggested that using tangent stiffness can provide convergence difficulty; therefore, a capped viscous damping formulation was proposed as a remedy for this problem. According to Charney [7], using displacement-based damping models (e.g., hysteretic or frictional damping) can simulate the energy dissipation more realistically compared to frequency-based models (e.g., viscous damping) however, using Rayleigh damping based on tangent stiffness was reported to be an appropriate approach for modeling damping. Chopra and McKenna [10] also proposed a new method for modeling damping named the superposition of modal damping matrices which tended to produce no spurious damping forces compared to other damping models. Luco and Lanzi [14] proposed a model for considering inherent damping in the inelastic time-history analyses which is based on the assumption that damping forces are proportional to the first derivative of the restoring forces with respect to the time. The proposed model was verified by the conventional damping modeling method-Rayleigh damping based on the tangent stiffness of the structure.

Another way of damping consideration coupled with modeling nonlinearity through concentrated plasticity formulation, which is the main focus of this paper, has been proposed by Medina and Krawinkler [3]; then, its enhancement was presented by Zareian and Medina [15]. In this approach, an element is changed to two rotational end springs with no assigned damping and an elastic part in the middle to which the modified initial stiffness proportional damping is assigned which is observable in Fig. 1. Since the modified element can be considered to be in series, the equation (2) can be written:

$$
K_{\text {original }}=\frac{K_{\text {spring }} K_{\text {elastic }}}{K_{\text {spring }}+K_{\text {elastic }}}
$$

$\mathrm{K}_{\text {original }}$ is the stiffness of the original element, $\mathrm{K}_{\text {spring }}$ is the rotational end spring stiffness, and $\mathrm{K}_{\text {elastic }}$ is the elastic stiffness of the middle part of the modified element.

The modified proportionality term is equal to:

$$
\beta^{\prime}=[(n+1) / n] \beta
$$


where " $n$ " is the ratio of rotational end springs stiffness to the stiffness of the elastic part of the element. This equation is derived from equivalence of the damping work done by springs plus the elastic part with the damping work done by the original element. Figure 1 demonstrates a schematic view of the typical element used in this methodology.

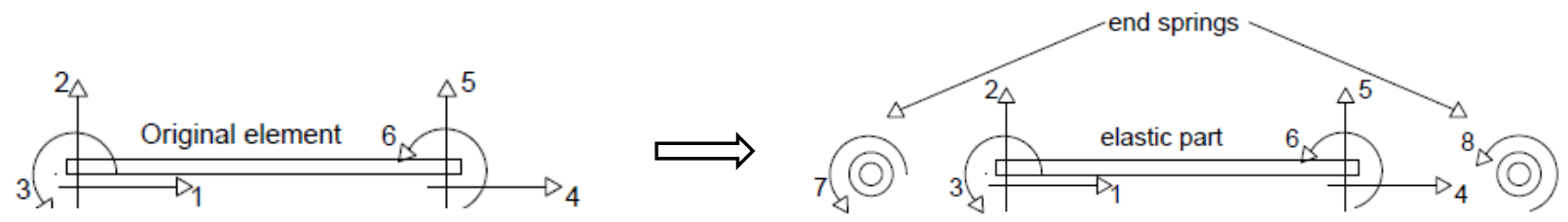

Figure 1. Equivalent element with depiction of degrees of freedom [15]

Medina and Krawinkler [3] suggested using $\mathrm{n}=10$ (i.e. $\mathrm{K}_{\text {elastic }}=1.1 \mathrm{~K}_{\text {original }}$ ) in order to compensate for allocating no damping to rotational springs. On the other hand, Zareian and Medina [15] stated that using $\mathrm{n}=10$ brings about difficulties in achieving convergence and the time step of the analysis should become very low; thereby, imposing numerical instabilities. Referring to Hall [16], using a great value for the initial rotational stiffness of springs may result in the underestimation of the building's response due to the large damping moments appeared as a result of relative velocity, occurring across the nodes. Yet, there is no consensus among researchers which ratio for the rotational spring stiffness to the stiffness of the elastic part of the element is appropriate to be used in this approach of modeling structural damping.

The objective of this paper is to evaluate the sensitivity of nonlinear responses and seismic performance and risk metrics of frames to the rotational end spring stiffness changes. The metrics include annual probability of collapse, mean repair cost, and annual repair cost. Studies in the literature primarily focused on the effects of using conventional or other proposed viscous damping modeling methods on the dynamic responses of models. This study aims to put one step forward and investigate how the change in stiffness ratio can affect the seismic risk metrics of a model which are critical for decision-making. In this research, 2, 4, and 8 story reinforced concrete (RC) moment frames were designed according to ACI 318-19 [17] and modeled by the proposed approach by Zareian and Medina [15] considering " $n$ " ratios equal to 1 to 10 for each frame. By simulating the models in OPENSEES program [18], Incremental Dynamic Analysis (IDA) [19] was performed, collapse fragility curves were derived, and seismic performance assessment was conducted based on the methodology introduced in FEMA P-58 [20]. 4 and 8-story moment frames were also modeled with the distributed plasticity formulation (according to the flexibility method, i.e. forcebased element developed in OPENSEES) and conventional Rayleigh damping with tangent stiffness for comparison purposes.

\section{Modeling Assumptions:}

RC moment frames were simulated through OPENSEES program. Studies done by Haselton et.al [21] were used to define the moment curvature behavior of end springs. The first and third modes were considered for calculating frequencies required for determining the proportionality terms (i.e. $a_{0}$ and $a_{1}$ in the equation (1) and $\beta^{\prime}$ in the equation (3)). Modal damping ratio was assumed to be 0.05 for 2 -story and 4-story and 0.035 for the 8-story frames, respectively. The modified stiffness proportional damping was assigned only to the elastic part of the elements in accordance with the methodology proposed by Zareian and Medina [15]. In order to consider the effects of confinement in concrete sections, the research done by Mander et.al are considered in the modeling details [22]. Other assumptions are shown in Table 1. Table 2 to Table 4 demonstrate the designed sections of frames.

Table 1. Design and modeling assumptions

\begin{tabular}{ll}
\hline Region & Los Angeles - USA \\
Occupancy & Commercial
\end{tabular}




$\begin{array}{ll}\text { Story height } & 3 \text { meters } \\ \text { Each bay's length } & 4 \text { meters }\end{array}$

Table 2. 2-Story Frame Sections (mm)

\begin{tabular}{ccc}
\hline Story Number & column section - reinforcement $(\mathrm{mm})$ & beam section (longitude*latitude) - reinforcement (mm) \\
\hline 2 & $250 * 250-8 \varphi 18$ & $200 * 150-4 \varphi 16$ \\
1 & $300 * 300-12 \varphi 18$ & $250 * 200-4 \varphi 18$ \\
\hline story number & Table 3. 4-Story Frame Sections (mm) & \\
\hline 4 & column section - reinforcement $(\mathrm{mm})$ & beam section (longitude*latitude) - reinforcement (mm) \\
\hline 3 & $300 * 300-12 \varphi 18$ & $350 * 300-8 \varphi 18$ \\
2 & $300 * 300-12 \varphi 18$ & $350 * 300-8 \varphi 18$ \\
1 & $350 * 350-12 \varphi 18$ & $400 * 350-8 \varphi 18$ \\
& $450 * 450-12 \varphi 18$ & $450 * 400-8 \varphi 18$ \\
story number & Table 4. 8-Story Frame Sections (mm) & \\
\hline 8 & column section - reinforcement (mm) & beam section (longitude*latitude) - reinforcement (mm) \\
\hline 6 & $300 * 300-12 \varphi 18$ & $300 * 250-6 \varphi 18$ \\
5 & $300 * 300-12 \varphi 18$ & $300 * 250-6 \varphi 18$ \\
4 & $400 * 400-12 \varphi 18$ & $350 * 300-8 \varphi 18$ \\
3 & $400 * 400-12 \varphi 18$ & $350 * 300-8 \varphi 18$ \\
2 & $450 * 450-12 \varphi 18$ & $450 * 400-8 \varphi 18$ \\
1 & $450 * 450-12 \varphi 18$ & $450 * 400-8 \varphi 18$ \\
& $500 * 500-16 \varphi 18$ & $500 * 450-8 \varphi 18$
\end{tabular}

\section{Incremental Dynamic Analysis:}

Based on the literature [19], analytically, collapse state is defined as when the drift ratio reaches $10 \%$, tangent (or instant slope) of the IDA curve gets $20 \%$ of the initial (elastic) slope, or as the occurrence of dynamic instability in the form of no convergence.

Interstory drift ratio and peak floor acceleration (PFA) are the two considered Engineering Demand Parameters (EDPs), which are both essential in the seismic performance assessment and loss estimation. Moreover, Intensity Measure (IM) is taken as the first mode spectral acceleration $\left(S_{\mathrm{a}}(\mathrm{T} 1,5 \%)\right)$. Ground motion records introduced in FEMA P-695 [23] (22 pairs of records) were used in the analyses.

Figure 2 to Figure 4 depict median IDA curves for all three frames. The median IDA curves associated with the $\mathrm{n}$ ratios equal to 1 to 10 in addition to the curves for the force-based model with conventional damping for the 4 and 8 -story frames are shown.
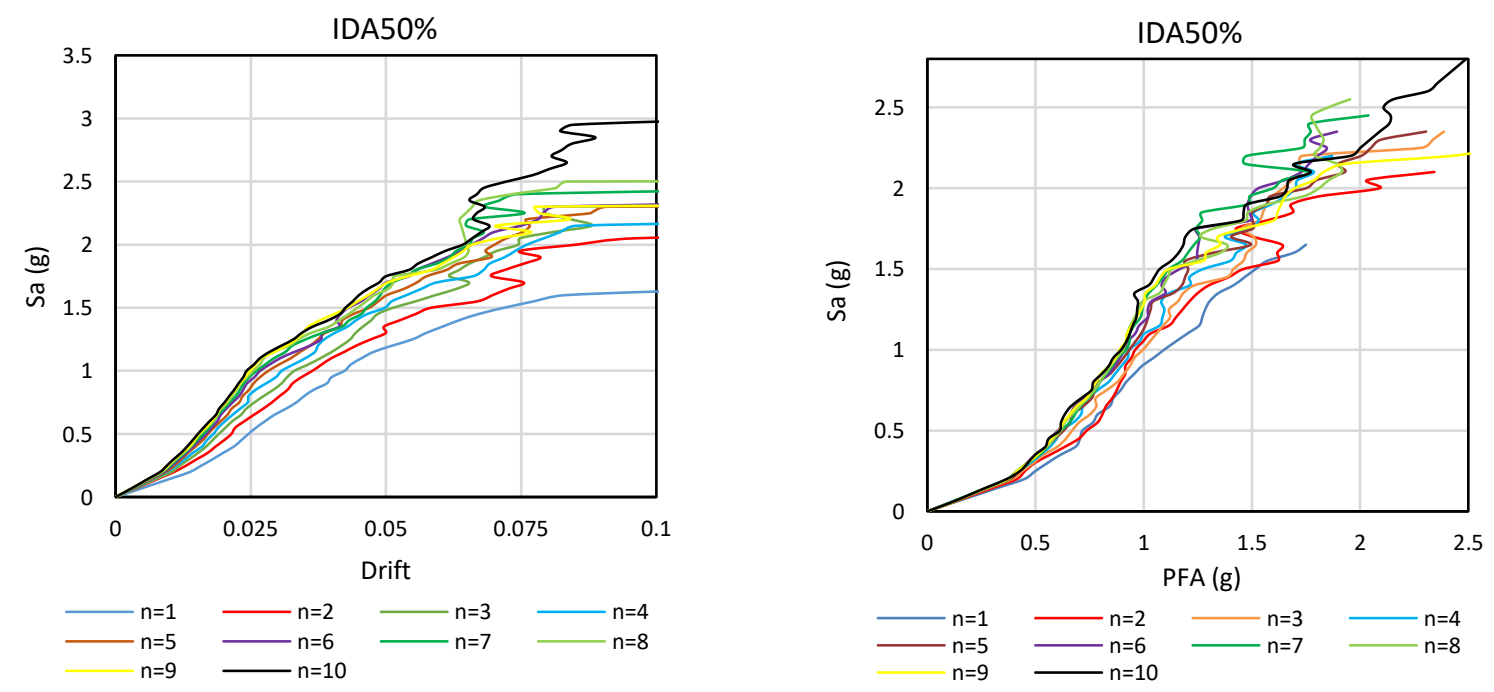
(a)

(b)

Figure 2. Median IDA curves for the 2-story moment frame with (a) EDP equal to interstory drift ratio and (b) EDP equal to the peak floor acceleration

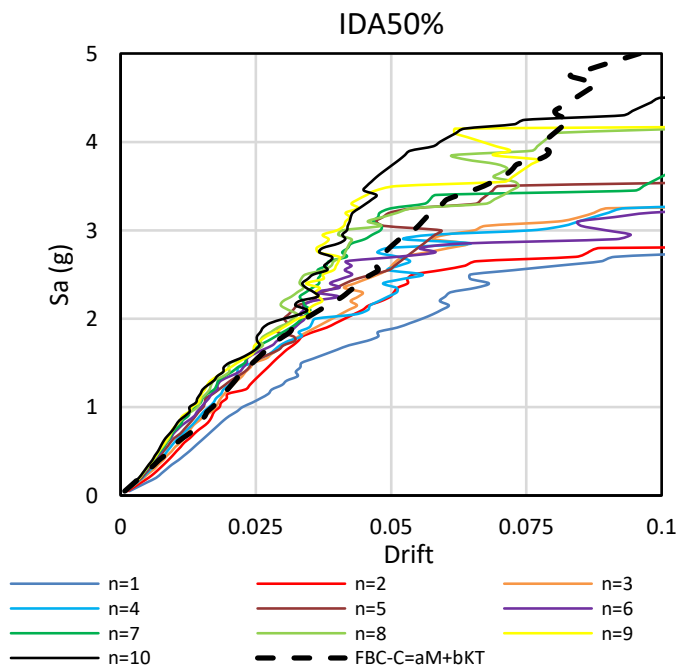

(a)

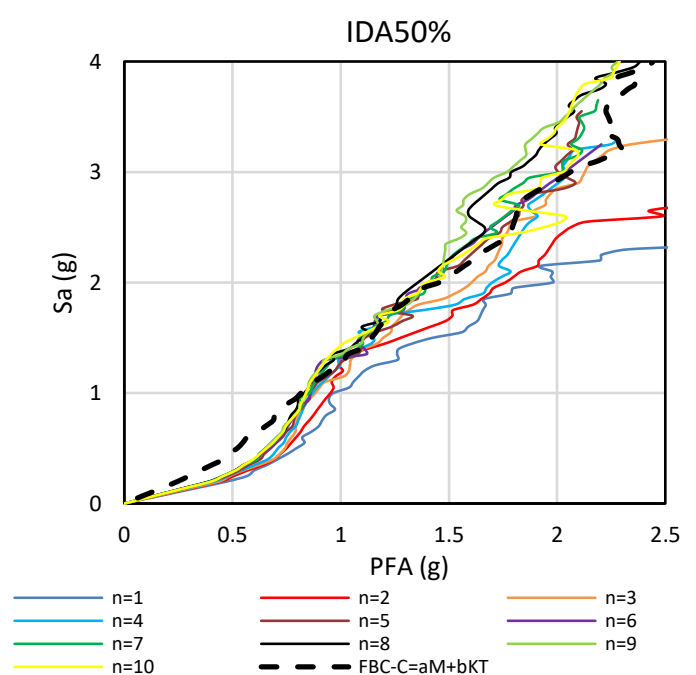

(b)

Figure 3. Median IDA curves for the 4-story moment frame with (a) EDP equal to interstory drift ratio and (b) EDP equal to the peak floor acceleration

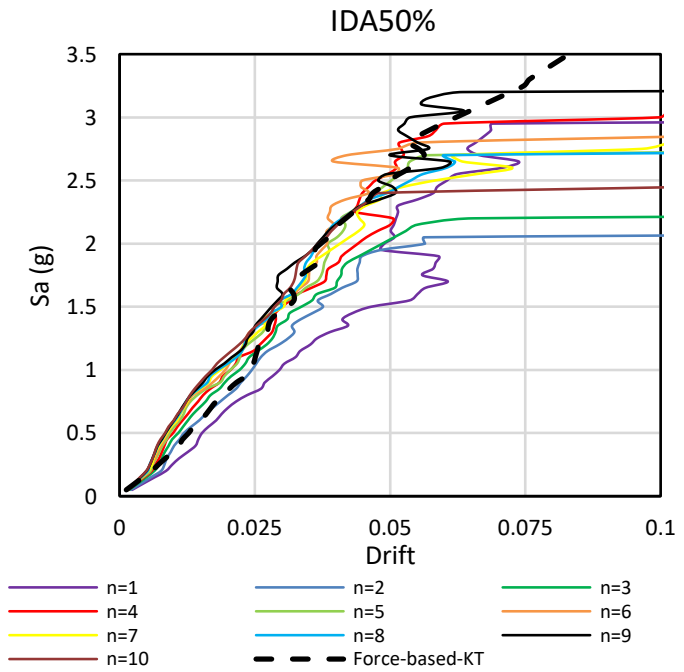

(a)

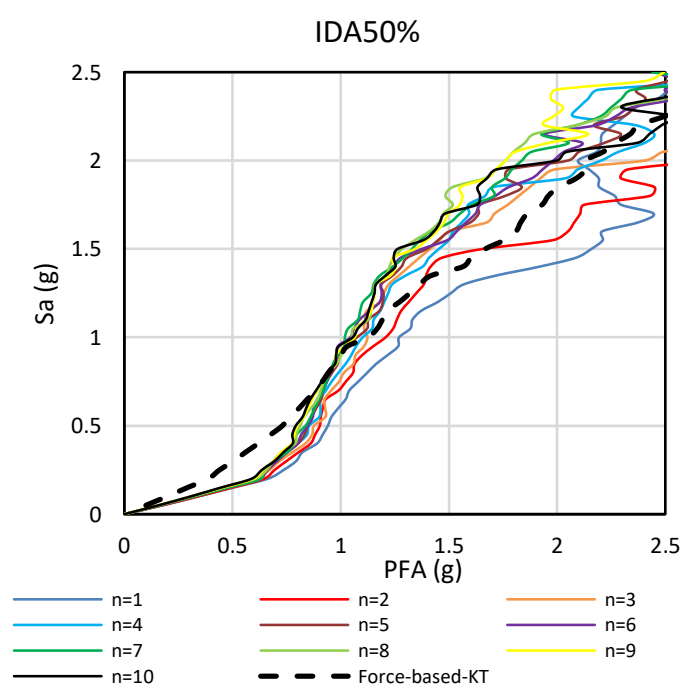

(b)

Figure 4. Median IDA curves for the 8-story moment frame with (a) EDP equal to interstory drift ratio and (b) EDP equal to the peak floor acceleration

As it is evident in Figure 2 to Figure 4, there is a considerable difference among the responses with various $n$ ratios. Noticeably, the more rigid rotational springs are used (i.e. the higher the $\mathrm{n}$ ratio), the lower is the estimation of demand parameters. However, in Figure 4, for the 8-story moment frame, there is not a consistent trend for $n=1$ to $n=10$. This may be due to the effects of the higher modes in modeling damping which is neglected by merely considering modes number 1 and 3. In spite of the inconsistency, in Figure 4, the curve corresponding to the model with $n=1$ is the lowest curve, overestimating the demand parameters in a specific intensity level compared to other curves. Comparing the fiber models (i.e. force-based with Rayleigh damping based on tangent stiffness) with concentrated plasticity models shows that the 
implementation of semi-rigid and rigid end rotational springs may result in approximately the same evaluation of the demand parameters as force-based models. Using a flexible spring, (i.e., implementing $\mathrm{n}=1$ ) may result in a highly conservative estimation of the drift and PFA compared to the other types of springs. It is worth noting that because of the scarcity of experimental data for selecting the accurate damping model and as there is still a contention among researchers about the use of tangent stiffness in Rayleigh damping models, the comparison of such models with the Rayleigh damping model based on tangent stiffness may not be an exact verification. However, it can provide an acceptable sense to see the effects of changing the end rotational stiffness on the structural responses; The structural responses from the analysis of concentrated plasticity models with different $n$ ratios can be compared with the responses derived from the damping models which are widely used for nonlinear simulation nowadays. The considerable difference in derived responses and the uncertainty of determining the accurate $\mathrm{n}$ ratio due to the lack of reliable experimental data, necessitate the investigation on the assessed strategy of modeling damping more profoundly.

\section{Collapse Assessment:}

Collapse assessment of RC frames was performed from two aspects: median collapse capacities were calculated, derived from collapse fragility curves; and annual probabilities of collapse were evaluated based on FEMA P-58 methodology..

\subsection{Collapse Fragility Curves and Median Collapse Capacity:}

In Figure 5, collapse fragility curves are illustrated, which show the probability of collapse corresponding to each level of intensity for each RC moment frame.

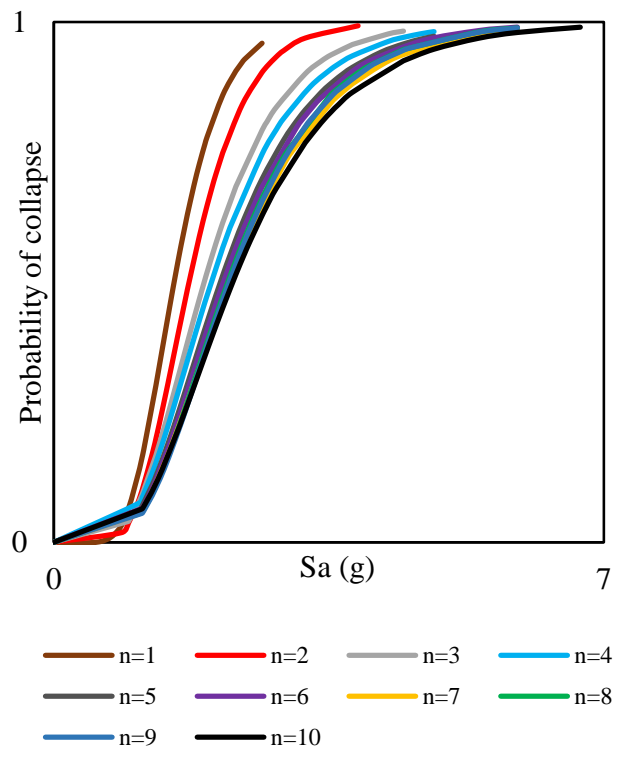

(a)

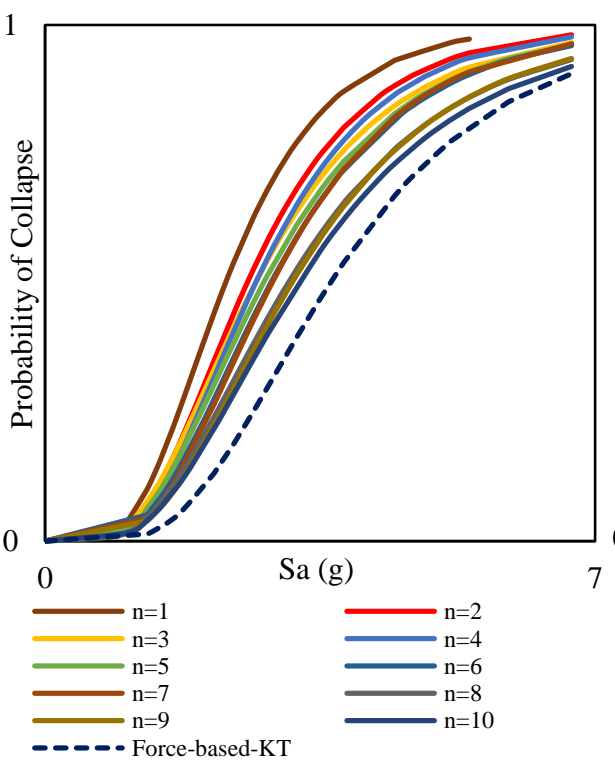

(b)

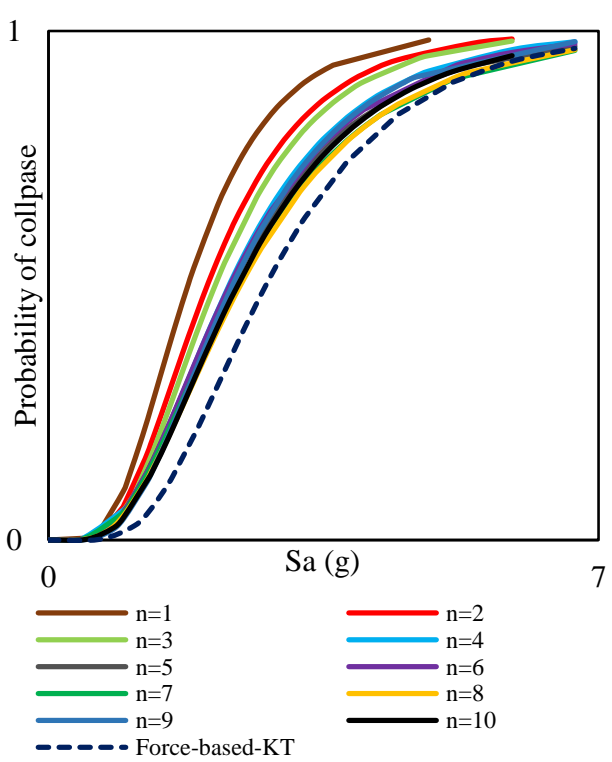

(c)

Figure 5. Collapse Fragility Curves for (a) 2-Story, (b) 4-Story, and (c) 8-Story moment frames 
According to Figure 5, there is a great difference among models with various $\mathrm{n}$ ratios in determining the collapse capacity of the building. For 2 and 4-story moment frames, using a flexible spring $(n=1)$ results in a higher probability of collapse in a specific intensity level. On the other hand, the implementation of a rigid spring $(\mathrm{n}=10)$ provides a low estimation of such value. Similar to the median IDA curves, although the same trend is not observable for the 8-story frame, still the highest and the lowest collapse fragility curves belong to the models with flexible and rigid springs, respectively.

From another aspect, in the 4 and 8 story frames, the fragility curves regarding the conventional damping model provide a lower estimation of the probability of collapse than the concentrated plasticity models in a specific intensity level, which implies that the damping model proposed by Zareian and Medina, which is investigated in this paper, is probable to overestimate the probability of collapse; or in other words, it can have a highly conservative estimate of the collapse capacity of the building provided that the conventional damping model based on the tangent stiffness of the structure is assumed to be the most accurate model. Accuracy among the available damping models can be defined as the close-to-reality evaluation of damping forces among all introduced remedies for considering damping forces in inelastic models. As it is mentioned earlier, there is no consensus among researchers that which damping model can estimate the damping forces accurately. No technique rather than the real shaking table tests can provide a definite verification for all proposed damping models.

In order to quantify the comparison of collapse capacities among all models developed in this study, the intensity level corresponding to the probability of collapse equal to 0.5 was taken from all curves named "median collapse capacity" (MCC). Table 5 indicates the MCCs for all considered models. Moreover, the bar chart in Figure 6 indicates a more straightforward comparison of MCCs.

Table 5. Median collapse capacities (g)

\begin{tabular}{cccc}
\hline Models & 2 Story Frame & 4 Story Frame & 8 Story Frame \\
\hline $\mathrm{n}=1$ & 1.531 & 2.296 & 1.773 \\
$\mathrm{n}=2$ & 1.721 & 2.570 & 2.020 \\
$\mathrm{n}=3$ & 1.920 & 2.676 & 2.120 \\
$\mathrm{n}=4$ & 2.006 & 2.678 & 2.296 \\
$\mathrm{n}=5$ & 2.120 & 2.780 & 2.338 \\
$\mathrm{n}=6$ & 2.158 & 2.872 & 2.306 \\
$\mathrm{n}=7$ & 2.238 & 2.888 & 2.410 \\
$\mathrm{n}=8$ & 2.216 & 3.094 & 2.441 \\
$\mathrm{n}=9$ & 2.231 & 3.139 & 2.341 \\
$\mathrm{n}=10$ & 2.278 & 3.244 & 2.408 \\
\hline Conventional damping model & & 3.630 & 2.766
\end{tabular}

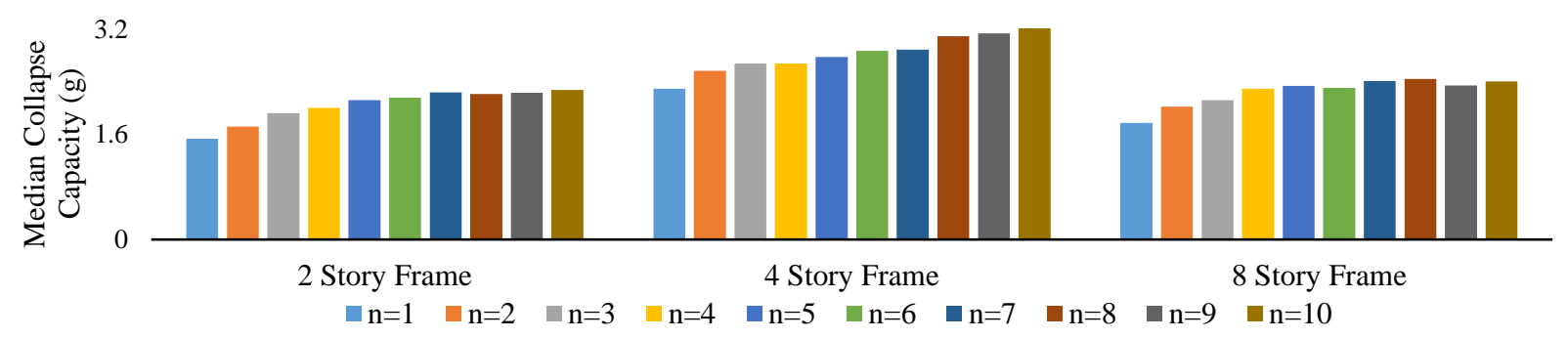

Figure 6. Median collapse capacities for all models

According to Table 5, MCC for the models with rigid springs $(n=10)$ is the closest ones to the MCC related to the conventional damping model. Nevertheless, for the 4 story frame, the MCC of the model with $\mathrm{n}=1$ is approximately 0.63 of the MCC of the conventional damping model. $37 \%$ difference between the 
derived collapse capacities cannot be negligible. Moreover, for the 8-story frame, the same difference is about $36 \%$ between the model with $\mathrm{n}=1$ and conventional damping model.

Figure 6 also shows that the more rigid the spring, the higher the evaluation of the MCC. There is not exactly the same pattern for MCCs of the 8-story frame as well as the median IDA and collapse fragility curves; however, the lowest estimation of the MCC is associated with the model with $\mathrm{n}$ ratio equal to 1. Dispersion indicators of the MCCs for merely the concentrated plasticity models are presented in Table 6.

Table 6. Dispersion indicators of MCCS for models with $n=1$ to $n=10$

\begin{tabular}{cccccc}
\hline Story & Range $(\%)$ & Median $(\mathrm{g})$ & Average $(\mathrm{g})$ & Variance & Standard deviation \\
\hline 2 & 32.79 & 2.12 & 2.042 & 0.056 & 0.237 \\
4 & 29.23 & 2.78 & 2.824 & 0.074 & 0.273 \\
8 & 26.37 & 2.338 & 2.245 & 0.041 & 0.201
\end{tabular}

\subsection{Annual Probability of Collapse:}

The integration of hazard curves with collapse fragility curves with the aid of a parameter named "mean annual frequency of collapse" $(\lambda c)$, leads to obtaining annual probability of collapse which can be considered as another indicator of collapse risk of structures [24]. Figure 7 indicates hazard curves of 2, 4, and 8 story frames derived from USGS database [25], considering the structural period of the designed frames and the soil characteristics of Los Angeles, CA [25].

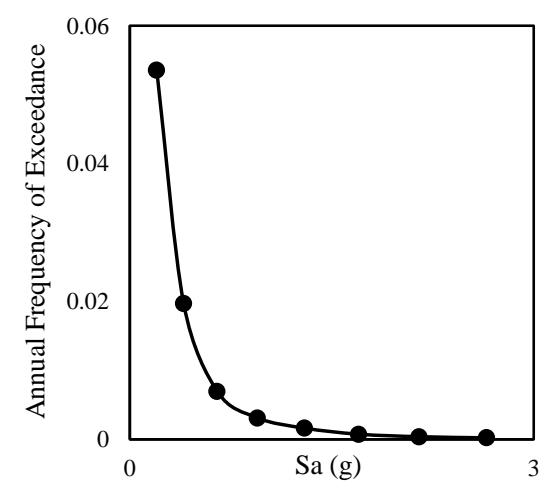

(a)

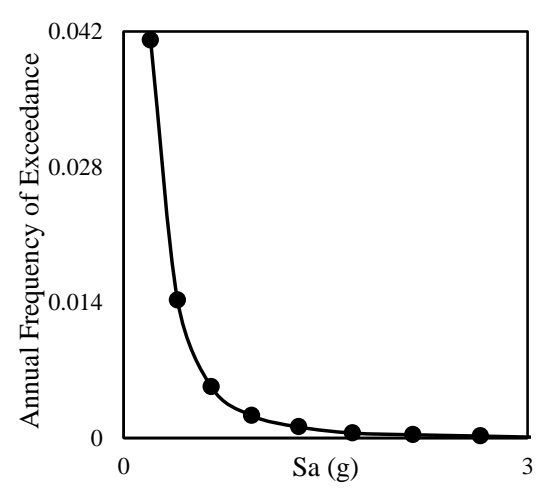

(b)

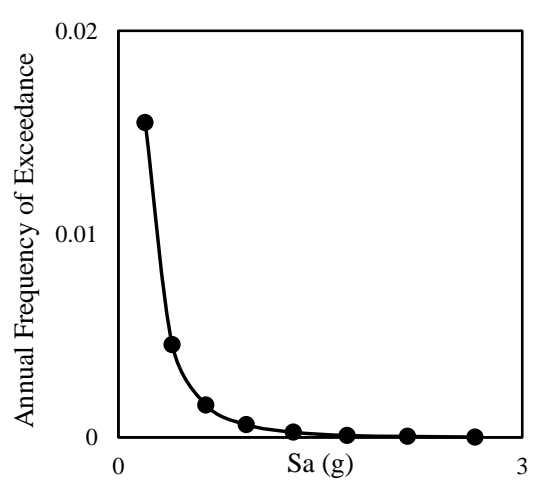

(c)

Figure 7. Hazard Curves for (a) 2-story, (b) 4-story, and (c) 8-story moment frames

In order to calculate seismic performance parameters, RC moment frames were modeled in the Performance Assessment Calculation Tool (PACT) introduced in FEMA P85 [26]. Building componentswere defined for all models similarly. Table 7 represents annual probabilities of collapse for all models. In order to have a visual comparison of this parameter, a bar chart is presented in Figure 8. 

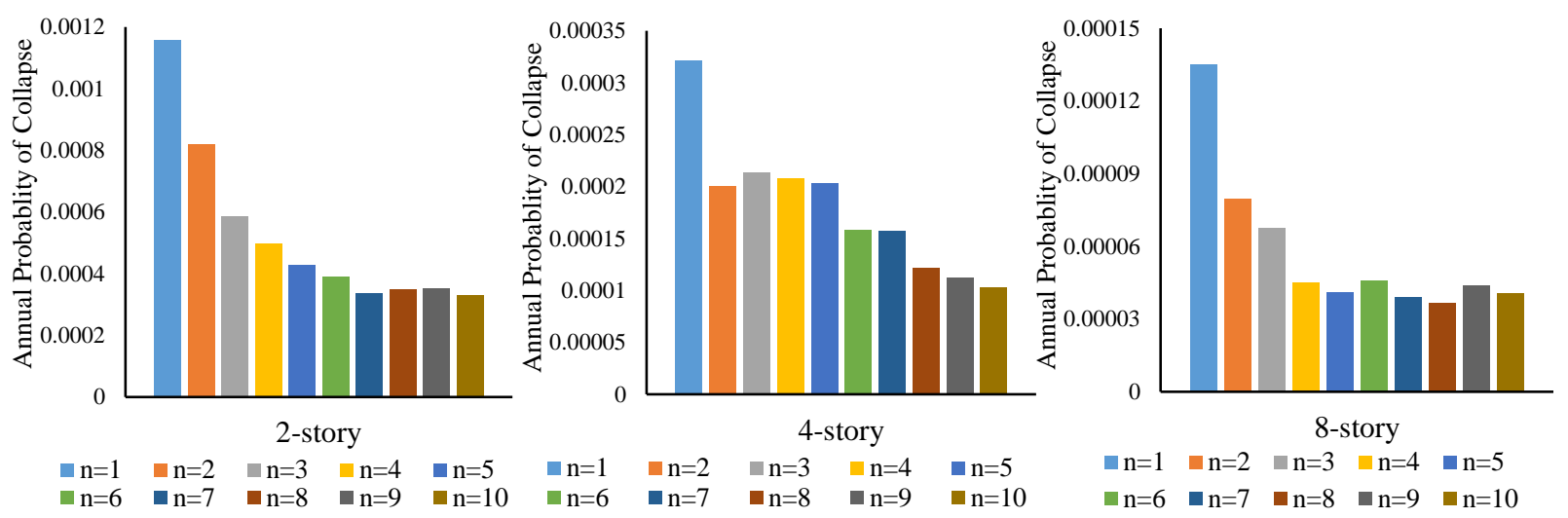

Figure 8 . Annual probability of collapse for the 2,4 , and 8 story frames

Table 7. Annual Probability of Collapse for all models

\begin{tabular}{cccc}
\hline Story number & 2 & 4 & 8 \\
\hline $\mathrm{n}=1$ & 0.001157765 & 0.00032129 & 0.00013523 \\
$\mathrm{n}=2$ & 0.000820373 & 0.000199824 & 0.000079685 \\
$\mathrm{n}=3$ & 0.000584824 & 0.000213201 & 0.000067595 \\
$\mathrm{n}=4$ & 0.000497623 & 0.000208073 & 0.000045216 \\
$\mathrm{n}=5$ & 0.000428894 & 0.000203383 & 0.000040876 \\
& & & \\
$\mathrm{n}=6$ & 0.000390267 & 0.000157589 & 0.000045696 \\
$\mathrm{n}=7$ & 0.000336061 & 0.000157123 & 0.000039114 \\
$\mathrm{n}=8$ & 0.000348758 & 0.000121616 & 0.000036599 \\
$\mathrm{n}=9$ & 0.000352995 & 0.000111892 & 0.000044051 \\
$\mathrm{n}=10$ & 0.000329127 & 0.000102646 & 0.000040476 \\
\hline Conventional damping model & 0.000056025 & 0.000017926
\end{tabular}

The remarkable sensitivity of the "annual probability of collapse" parameter to the change of the end rotational springs' stiffness can be seen in Figure 8. There is a considerable difference between the annual probability of collapse regarding the model with flexible springs $(n=1)$ and models with rigid and semirigid springs. According to Table 7 , the annual probability of collapse for the model with $\mathrm{n}=1$ is approximately $3.52,3.13$, and 3.34 times more than the model with $\mathrm{n}=10$ for 2,4 , and 8 story frames, respectively. This means that using a flexible spring brings about a highly conservative estimation of this parameter. Although it is not possible to definitely state that which model is the most accurate one due to the lack of experiments on damping models, observing such differences in both collapse parameters (median collapse capacity and annual probability of collapse) is significant to be considered. Another point to mention is that the annual probability of collapse for the conventional damping model is evaluated to be roughly the half of the same quantity for the concentrated plasticity models with rigid springs $(n=10)$, which itself has the lowest amount among the concentrated plasticity models. It can be concluded that this damping model provides a highly conservative estimation of the annual probability of collapse if the conventional damping model is assumed to be an acceptable damping model; otherwise, this damping modeling method (proposed by Zareian and Medina [15]) requires more investigation or verification with the experimental data.

\section{Loss Estimation:}

Evaluating building losses, such as casualties or repair costs, is a helpful asset for decision makers. To this end, it is required to determine building components and their fragility and consequence functions which are derived from experiments or numerical research. In this paper, mean repair cost and expected 
annual repair cost are the two metrics considered for the loss estimation of concentrated plasticity modeled frames.

\subsection{Mean repair Cost:}

Considering the total building's collapse fragility curve and each component's fragility function, by the integration of the repair costs associated with each component, the building's mean repair cost can be calculated through calculating the average of repair costs from a set of Monte Carlo realizations. When collapse occurs for a specific component, based on the building's response to the seismic load and its fragility curve, its repair cost would be equivalent to its predefined replacement cost [20], which is assumed to be the same for all three buildings only for the matter of convenient comparison. A total number of 5000 Monte Carlo realizations was considered for all the models in this study.

Figure 9 depicts mean repair costs normalized by total building's replacement cost with respect to each intensity level for 2,4 , and 8 story frames respectively. The difference among models is observable in terms of this parameter as well as previous ones.

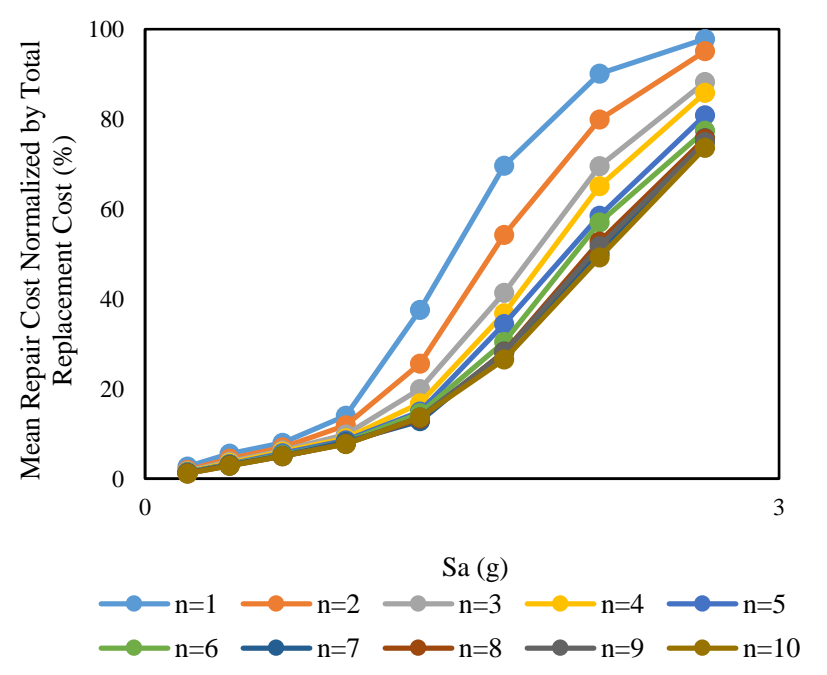

(a)

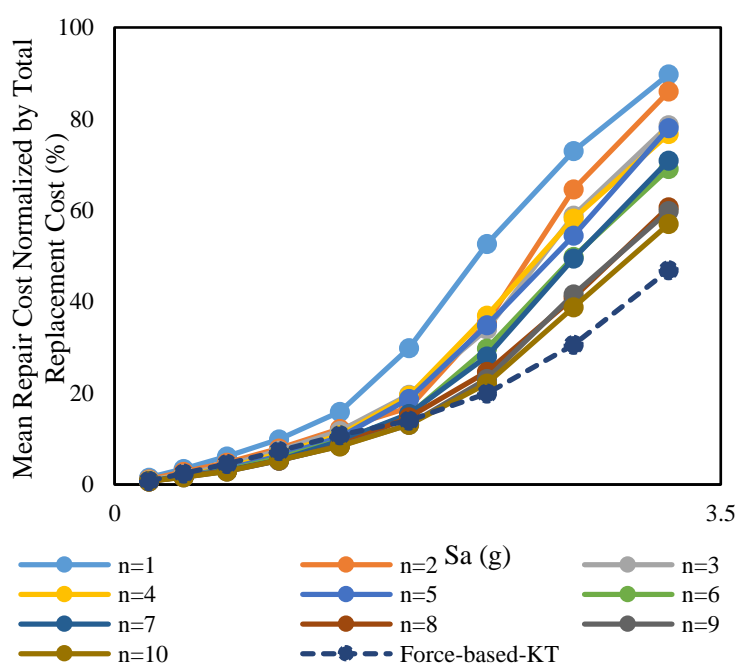

(b)

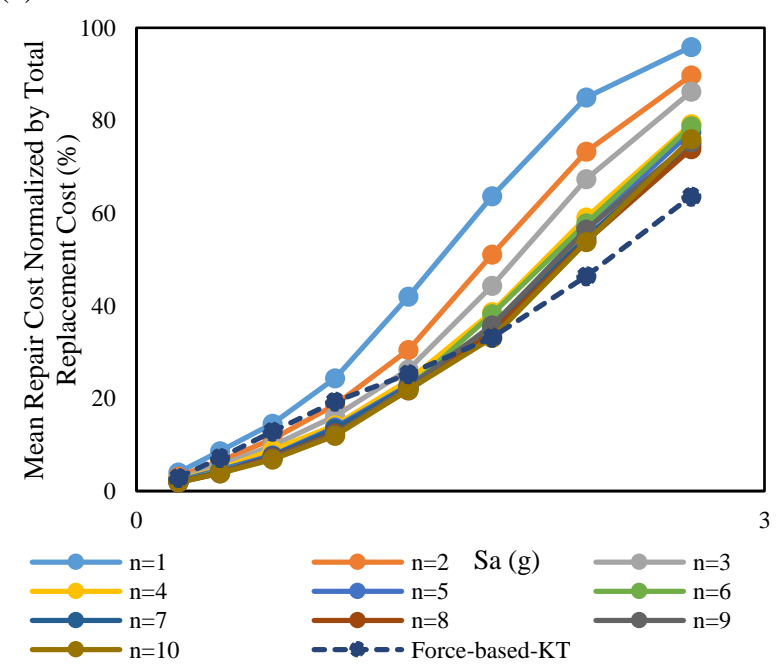

(c)

Figure 9. Mean repair cost normalized by total replacement cost for (a) 2-story, (b) 4-story, and (c) 8 story moment frames 
According to Figure 9, the highest value of the mean repair cost is associated with the model with the flexible end rotational spring and the lowest one is related to the model with rigid springs $(n=10)$ for all three RC moment frames. The difference between the highest and lowest mean repair cost in the intensity level equal to $2.65 \mathrm{~g}$ is about $24.2 \%, 32.7 \%$, and $19.8 \%$ for 2,4 , and 8 -story moment frames, respectively, which is a considerable difference. It shows that the implementation of flexible springs results in a greatly conservative estimation for this performance parameter compared to other types of spring. It can be concluded that the analyst willing to model the structure via concentrated plasticity formulation with the damping strategy studied in this paper, should be aware of the considerable impact of end springs' stiffness selection on the probable repair cost of the building due to the ground motion. Consequently, the necessity of conducting more profound assessment on such model should be raised. In addition, the comparison of the mean repair costs presented in Figure 9.b and Figure 9.c indicates that the conventional damping model based on the tangent stiffness provides much less estimation of such parameter than the concentrated plasticity models; in the 4-story frame, the mean repair cost of the conventional damping model is roughly $42 \%$ less than the model with $n=1$ and $10 \%$ less than the model with $n=10$. Similarly, for the 8 -story frame, the mean repair costs of the model with $n=1$ and $n=10$ are about $32 \%$ and $12 \%$ greater than the conventional damping model, respectively.

\subsection{Expected Annual Loss:}

Expected Annual Loss (EAL) can be considered as a consequential parameter for stakeholders. EAL can be calculated by integrating building repair costs normalized by replacement costs over passible hazard frequencies, [27], which can be ordinarily defined as the amount of money required annually to repair probable damages caused by the earthquake.

Table 8 comprises expected annual financial loss for all models. As well as the annual probability of collapse, this parameter is illustrated by a bar chart in Fig. 12 in order to simplify visual comparison of all models.

Table 8. Expected Annual Loss (EAL) (\$)

\begin{tabular}{cccc}
\hline Story Number & 2 & 4 & 8 \\
\hline $\mathrm{n}=1$ & 90456 & 43947 & 34433 \\
$\mathrm{n}=2$ & 71715 & 34454 & 26558 \\
$\mathrm{n}=3$ & 61821 & 30249 & 22877 \\
$\mathrm{n}=4$ & 56677 & 27979 & 20378 \\
$\mathrm{n}=5$ & 52643 & 26430 & 18905 \\
$\mathrm{n}=6$ & 49957 & 24484 & 17934 \\
$\mathrm{n}=7$ & 47626 & 23882 & 17632 \\
$\mathrm{n}=8$ & 46791 & 22493 & 17007 \\
$\mathrm{n}=9$ & 46136 & 21976 & 16653 \\
$\mathrm{n}=10$ & 45260 & 21483 & 16364
\end{tabular}
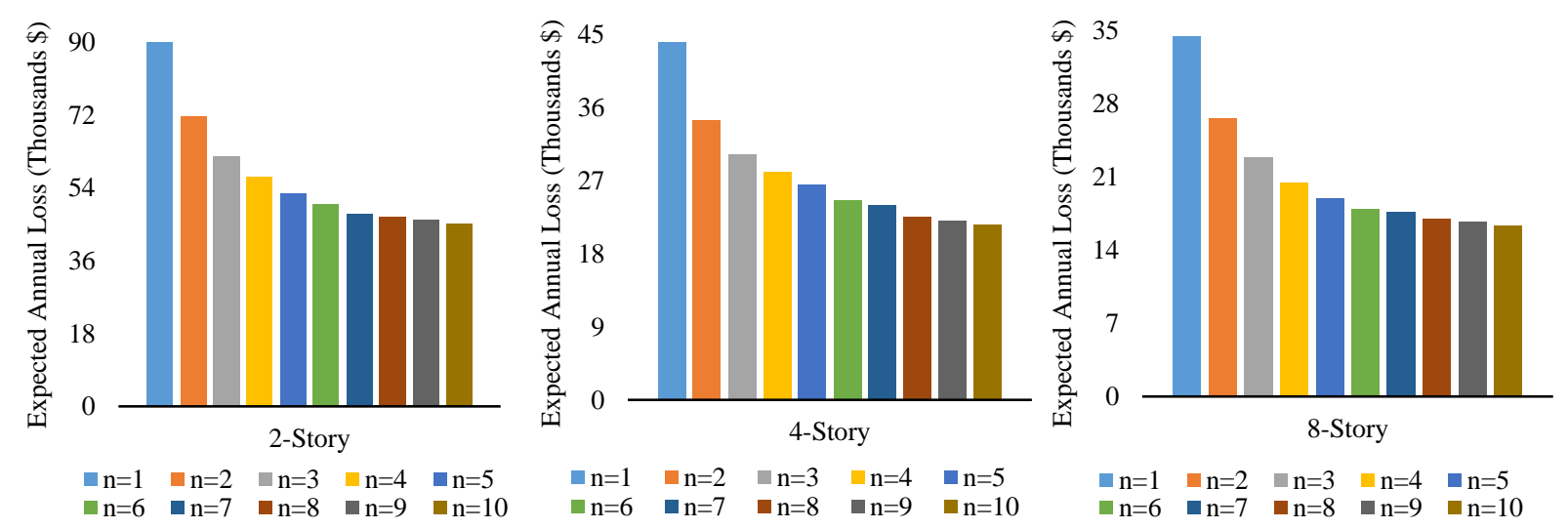

Figure 10. Expected annual loss for the 2, 4, and 8 story frames 
Approximately the same trend as the annual probability of collapse is apparent for this parameter. As shown in Figure 10, a great difference between the models with rigid and flexible springs in terms of EAL can be observed for all 2, 4, and 8-story frames. This difference is considerable to the extent that the EAL of the model with $n=1$ is approximately 2 times greater than the model with $n=10$ for all three frames. By comparing such differences to the same difference for annual probability of collapse in section 4.2 which was $3.52,3.13$, and 3.34 for 2, 4, and 8-story frames respectively, it can be concluded that the "expected annual loss" is a little less sensitive to changing stiffness of end rotational springs in concentrated plasticity modeling method than "annual probability of collapse" parameter. Nevertheless, the dispersion of EALs for each frame is still substantial. For instance, if the analyst chooses to implement a flexible spring in the model, the expected annual loss, is going to be $\$ 43947$ for a 4 story frame which is 2 times greater than the model in which rigid end springs are used. This may encourage the researchers to reconsider this model in terms of choosing an appropriate $\mathrm{n}$ ratio and may spur them to investigate on this damping modeling technique more in depth.

\section{Conclusion:}

In this paper, the previously proposed concentrated plasticity modeling technique for considering viscous damping in structures was evaluated. The effect of changing a specific and critical parameter, which is the ratio of the stiffness of the end rotational springs to the elastic part of the modified element (or $n$ ratio), on the seismic responses via IDA analysis was investigated in terms of interstory drift ratio and peak floor acceleration. The sensitivity analysis in terms of modifying the " $n$ " ratio was performed on the seismic performance parameters critical for decision-making including the annual probability of collapse, mean repair cost, and expected annual loss. Collapse assessment was performed considering median collapse capacity and annual probability of collapse. Three RC moment frames with various heights $(2,4$, and 8 story frames) and with ten types of end rotational springs, comprising rigid $(n=10)$ to flexible $(n=1)$, were selected. In order to compare the results to the conventional damping model which is the Rayleigh damping based on mass and tangent stiffness matrix, the 4 and 8 -story moment frames were also modeled considering such damping modeling strategy. In these 2 models, the elements were simulated based on the flexibility method, using the "force-based element" available in OPENSEES, which has the potential to have nonlinear behavior in each section of the element according to the stress-strain relationship assigned to each fiber section. Then, the responses and performance parameters of all models were compared.

There has been a debate on finding the appropriate $\mathrm{n}$ ratio for this damping modeling approach in the literature. However, according to the research done in this paper, although it is not feasible to firmly state which model provides the closest response to the real response of the structure due to the lack of experimental data, it is clear that using flexible rotational end springs provides a highly conservative estimation of collapse capacity and building loss in comparison with other types of springs. The remarkable differences between results in terms of the parameters assessed in this research for various $n$ ratios make this model considerably sensitive to the selection of the appropriate $\mathrm{n}$ ratio. Moreover, by comparing the responses derived from the conventional damping model with the model under investigation in this paper, it can be seen that the implementation of a rigid and semi-rigid spring (e.g. $n=10$ ) provides more similar results to the conventional damping model. However, it is important to note that there is still a contention on the accuracy of using tangent stiffness in the Rayleigh damping model in the literature. Only if the conventional damping model used in this research is assumed to be the most acceptable model among all introduced remedies, it can be asserted that using a rigid or semi-rigid springs provides more accurate results. Consequently, a more profound research is required to firstly define the appropriate damping model, and secondly determine the most exact $\mathrm{n}$ ratio which can accurately simulate buildings' behavior. This may be probable by comparing results derived from experiments with numerical results in future. 


\section{References:}

[1] Terzic V. Force-based element vs. Displacement-based element. Univ Berkeley, OpenSees, NEES, NEEScomm 2011.

[2] Aghajani Delavar M, Salehi M, Sideris P. Gradient inelastic force-based formulation for damage and failure of shear critical RC members. 17th World Conf. Earthq. Eng. 17WCEE, 2020.

[3] Medina R, Krawinkler H. Seismic demands for nondeteriorating frame structures and their dependence on ground motions 2004:1-347.

[4] Deierlein GG, Reinhorn AM, Willford MR. Nonlinear Structural Analysis For Seismic Design: A Guide for Practicing Engineers. NEHRP Seism Des Tech Br No 4 2010:36.

[5] Chopra AK. Dynamics of Structures: Theory and applications to earthquake engineering. 18th ed. Englewood Cliffs; 1995.

[6] Hall JF. Problems encountered from the use (or misuse) of Rayleigh damping. Earthq Eng Struct Dyn 2006;35:525-45. doi:10.1002/eqe.541.

[7] Charney F a. Unintended Consequences of Modeling Damping in Structures. J Struct Eng 2008;134:581-92. doi:10.1061/(ASCE)0733-9445(2008)134:4(581).

[8] Erduran E. Evaluation of Rayleigh damping and its influence on engineering demand parameter estimates. Earthq Eng Struct Dyn 2012;41:1905-19. doi:10.1002/eqe2164.

[9] Petrini L, Maggi C, Priestley MJN, Calvi GM. Experimental Verification of Viscous Damping Modeling for Inelastic Time History Analyzes. J Earthq Eng 2008;12:125-45. doi:10.1080/13632460801925822.

[10] Chopra AK, Mckenna F. Modeling viscous damping in nonlinear response history analysis of buildings for earthquake excitation. Earthq Eng Struct Dyn 2015;45:193-211. doi:10.1002/eqe.2622.

[11] Hardyniec A, Charney F. An investigation into the effects of damping and nonlinear geometry models in earthquake engineering analysis. Earthq Eng Struct Dyn 2015;44:2695-715. doi:10.1002/eqe.2604.

[12] Mohammadgholibeyki N, Banazadeh M. The Effects of Viscous Damping Modeling Methods on Seismic Performance of RC Moment Frames Using Different Nonlinear Formulations. Structures 2018;15:232-43. doi:10.1016/J.ISTRUC.2018.07.009.

[13] Anajafi H, Medina RA, Santini-Bell E. Effects of the improper modeling of viscous damping on the first-mode and higher-mode dominated responses of base-isolated buildings. Earthq Eng Struct Dyn 2020;49:51-73.

[14] Luco JE, Lanzi A. A new inherent damping model for inelastic time-history analyses. Earthq Eng Struct Dyn 2017;46:1919-39. doi:10.1002/eqe.2886.

[15] Zareian F, Medina RA. A practical method for proper modeling of structural damping in inelastic plane structural systems. Comput Struct 2010;88:45-53. doi:10.1016/j.compstruc.2009.08.001.

[16] Hall J. Discussion of "Modelling viscous damping in nonlinear response history analysis of buildings for earthquake excitation" by Anil K.Chopra and Frank McKenna. Earthq Eng Struct Dyn 2016:657-75. doi:10.1002/eqe.2761.

[17] 318 ACIC. Building Code Requirements for Structural Concrete (ACI 318-19): An ACI Standard; 
Commentary on Building Code Requirements for Structural Concrete (ACI 318R-19), American Concrete Institute; 2020.

[18] OPENSEES. Open System for Earthquake Engineering Simulation. Pacific Earthq Eng Res Center, Univ Calif Berkeley, CA 2002. http://opensees.berkeley.edu/ (accessed March 17, 2016).

[19] Vamvatsikos D, Cornell CA. The Incremental Dynamic Analysis and Its Application To Performance-Based Earthquake Engineering. Eur Conf Earthq Eng 2002:10. doi:10.1002/eqe.141.

[20] FEMA P58- Federal Emergency Management Agency. Seismic Performance Assessment of Buildings Volume 1- methodology. Appl Technol Counc 2012;1:278.

[21] Haselton CB, Liel AB, Lange ST. Beam-Column Element Model Calibrated for Predicting Flexural Response Leading to Global Collapse of RC Frame Buildings. vol. 03. 2008.

[22] Mander JB, Priestley MJN, R.Park. Theoretical Stress Strain Model for Confined Concrete. J Struct Eng 1988;114:1804-25. doi:10.1061/(ASCE)0733-9445(1988)114:8(1804).

[23] FEMA P695- Federal Emergency Management Agency. Quantification of building seismic performance factors. Appl Technol Counc 2009:421.

[24] Eads L, Miranda E, Krawinkler H, Lignos DG. Improved Estimation of Collapse Risk for Structures in Seismic Regions. Fifteenth World Conf Earthq Eng 2012.

[25] USGS. United States Geological Survey n.d. https://earthquake.usgs.gov/hazards/ (accessed June 12, 2016).

[26] FEMA P58- Federal Emergency Management Agency. Seismic Performance Assessment of Buildings Volume 2 - Implementation Guide. Appl Technol Counc 2012;2:357.

[27] Dhakal RP, Mander JB. Financial Risk Assessment Methodology for Natural Hazards. Bull New Zeal Soc Earthq Eng 2006:91-105. 